\title{
Особенности динамики заболеваемости населения Сибирского приграничья в 1995-2015 гг. ${ }^{1}$
}

СОБОЛЕВА С.В., доктор экономических наук. E-mail: soboleva@ieie.nsc.ru СМИРНОВА Н.Е., ЧУДАЕВА О.В., Институт эКОНомики и организации промышленного производства СО РАН, Новосибирск

Цель работы - показать особенности динамики заболеваемости населения Сибирского приграничья за период 1995-2015 гг. на фоне изменения заболеваемости населения Сибирского федерального округа и остальных федеральных округов РФ. СФО в последние годы занимает первые места по многим классам заболеваемости, и в первую очередь по вносящим основной вклад в смертность и инвалидизацию населения. В самом СФО резко выделяется в негативную сторону Алтайский край с самым высоким уровнем заболеваемости, в том числе болезнями системы кровообращения и новообразованиями. Показано, что видимое относительное благополучие с заболеваемостью населения в регионах Восточно-Сибирского приграничья связано с более молодой возрастной структурой. Ключевые слова: демографический потенциал, здоровье населения, заболеваемость, основные классы болезней, структура смертности, ожидаемая продолжительность жизни

Особое внимание к территориям Сибирского приграничья связано с результатами проведенного авторами исследования оценки демографической безопасности субъектов Сибирского федерального округа (СФО) с использованием интегрального показателя демографической безопасности ${ }^{2}[1,2]$, которое показало, что самыми неблагополучными регионами СФО являются территории, граничащие с Казахстаном, Монголией и Китаем.

\footnotetext{
${ }^{1}$ Статья подготовлена в рамках Проекта ІІ.2П/ХІ.179-1 (0325-2015-0018) «Социально-экономические и ресурсные аспекты трансграничного сотрудничества приграничных регионов Сибири».

${ }^{2}$ Интегральный показатель демографической безопасности построен на основе следующих базовых показателей: естественный прирост населения; суммарный коэффициент рождаемости; ожидаемая продолжительность жизни; число прерываний беременности (абортов) на 100 родов; коэффициент демографической нагрузки (численность детей и населения старше трудоспособного возраста на 1000 человек трудоспособного возраста); коэффициент замещения (численность детей на 1000 человек старше трудоспособного возраста).
} 
Регионы так называемого Сибирского приграничья ${ }^{3}$ требуют повышенного внимания как со стороны исследователей проблем безопасности, так и властей федерального и регионального уровней для принятия соответствующих управленческих решений с целью обеспечения демографической и национальной безопасности.

Депопуляционные процессы в течение длительного времени в сочетании с активным миграционным оттоком населения привели не только к сокращению численности населения и количества населенных пунктов Сибирского приграничья (особенно в сельской местности), но и к значительному ухудшению возрастной структуры его населения [3-5]. Так, в Сибирско-Казахстанском приграничье в 2001-2010 гг. сокращение затронуло, прежде всего, численность и долю детей (0-15 лет), а в 2010-2015 гг. численность и долю населения трудоспособного возраста. При этом численность и доля населения старше трудоспособного возраста за эти периоды, наоборот, росли нарастающим темпом. В будущем, соответственно, будет происходить рост демографической нагрузки за счет увеличения числа иждивенцев в расчете на одного трудоспособного. Особенно высок будет вклад в общую демографическую нагрузку пожилых людей, что повлечет рост социальных расходов на поддержку всей инфраструктуры, обслуживающей пожилое население.

Пропорционально уменьшению численности населения сокращалась в приграничных районах и его плотность в расчете на один квадратный километр. Например, по данным переписи 2010 г., в полосе таких районов Новосибирской области плотность населения в 2,4 раза меньше средних по области данных, в Омской области - в 1,8 раза, в Алтайском крае - в 1,4 раза, в Республике Алтай - в 1,7 раза, и разрыв постоянно увеличивается. Следствием низкой плотности населения является низкая экономическая плотность и обезлюдевание приграничных территорий. Все это не способствует развитию экономики и представляет собой угрозу территориальной целостности и национальной безопасности.

${ }^{3}$ Территорию Сибирского приграничья составляют Омская, Новосибирская области, Алтайский край и частично Республика Алтай, граничащие с Казахстаном,Сибирско-Казахстанское приграничье; Республика Алтай (частично), Республика Тыва и Республика Бурятия, граничащие с Монголией, а также Забайкальский край, имеющий границу с Монголией и Китаем,- Восточно-Сибирское приграничье.
Кроме количественной оценки, демографический потенциал государства (территории) существенно зависит и от качественных характеристик населения, важнейшая из которых - здоровье [6-8].

В комплексную оценку здоровья входит заболеваемость населения, которая определяется на основе данных об обращаемости населения за медицинской помощью - по числу случаев заболеваний, выявленных в течение года всеми медицинскими учреждениями и при проведении профилактических осмотров. Отношение числа зарегистрированных случаев заболеваний к среднегодовой численности постоянного населения территории определяет уровень заболеваемости (частоту распространения заболеваний).

Цель данной работы - показать особенности динамики заболеваемости населения регионов Сибирского приграничья за 1995-2015 гг. и дать оценку влияния состояния здоровья населения на его демографический потенциал. Для этого мы наряду со статистическими показателями данных об обращаемости населения за медицинской помощью будем рассматривать и показатели смертности населения по отдельным классам болезней. Такое сравнение позволит дать более точную объективную оценку заболеваемости населения.

Особое внимание уделено анализу трендов заболеваемости по классам, доминирующим в структуре смертности населения. В 2015 г. около половины всех смертей в СФО приходилось на смертность от болезней системы кровообращения - $46 \%$ (в РФ-49\%), далее следуют новообразования - $16 \%$ (в РФ - $16 \%$ ) и внешние причины смерти - $12 \%$ (в РФ - 9\%). Таким образом, эти три класса причин смертности в сумме составляли в СФО, как и в РФ, 74\% всех смертей.

Информационную базу исследования составили данные Росстата за 1995-2015 гг.

\section{Первичная заболеваемость населения территорий Сибирского приграничья и СФО}

На протяжении 1992-2015 гг. в постсоветской России наблюдалась тенденция роста заболеваемости ${ }^{4}$ населения с некоторой

\footnotetext{
4 Здесь и далее: под этим термином понимается число зарегистрированных заболеваний у больных с диагнозом, установленным впервые в жизни, на 1000 человек населения.
} 
стабилизацией в 2009-2015 гг. Позиции СФО по заболеваемости ухудшились с предпоследней среди федеральных округов в 1997-1998 гг. до второй-третьей после Приволжского и Северо-Западного федеральных округов в 2011-2015 гг. С 2000 г. в округе показатели заболеваемости были выше среднероссийского уровня, и в последние годы разрыв увеличивался: в 2010 г. заболеваемость населения в СФО на 5\%, а в 2015 г.- уже на 9\% выше, чем в среднем по России. В 2015 г. заболеваемость населения в СФО составила 848 на 1000 человек населения и выросла с 1992 г. на $32 \%$ (в РФ - на 26\%).

Существенно лучшая ситуация с заболеваемостью отмечена в Южном и, особенно, в Северо-Кавказском федеральных округах. Это подтверждается и более высокой продолжительностью жизни в этих округах, чем в среднем по стране.

Из субъектов Сибирского приграничья выделяется Алтайский край, где в 2015 г. заболеваемость населения была на 29\% выше, чем в среднем по СФО. На 9\% выше средних по округу показатели заболеваемости в Омской области и на $6 \%$ - в Республике Алтай (рисунок). На общем неблагоприятном фоне несколько лучше ситуация в республиках Бурятия и Тыва, а также в Забайкальском крае и Новосибирской области.

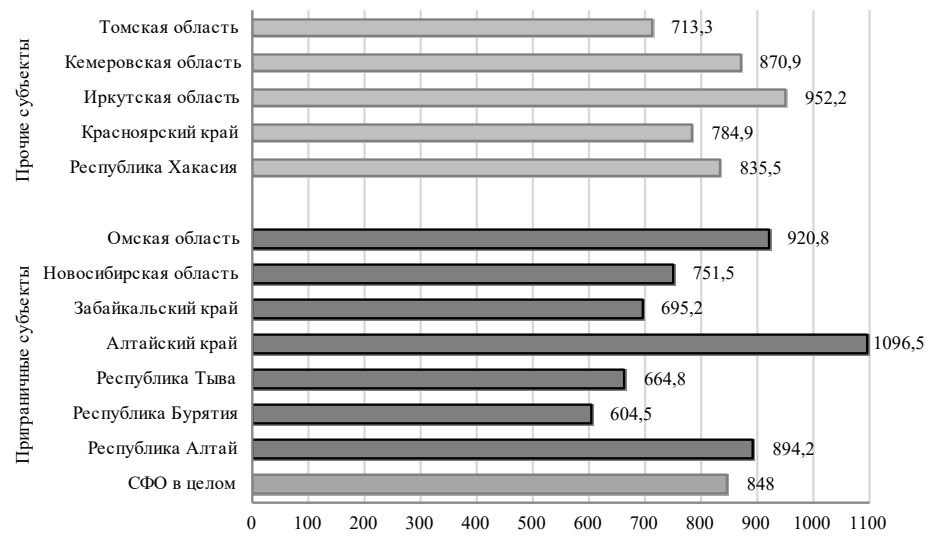

Заболеваемость населения в субъектах СФО в 2015 г. (зарегистрировано заболеваний у больных с диагнозом, установленным впервые в жизни, на 1000 человек населения)
Однако эти регионы, за исключением Новосибирской области, на протяжении длительного времени характеризуются ожидаемой продолжительностью жизни ниже средней по СФО. Особенно это касается Республики Тыва, которая занимает последнее место в стране по ожидаемой продолжительности жизни. В Новосибирской области, напротив, ожидаемая продолжительность жизни выше средней по СФО (второе место в округе после Томской области).

В структуре заболеваемости населения Сибирского приграничья в 2015 г. высокую долю составляли болезни органов дыхания $-39,8 \%$ (в СФО - 39,0\%), травмы, отравления и некоторые другие последствия воздействия внешних причин - 10,7\% (в СФО - 11,8\%), болезни нервной системы и органов чувств $9,2 \%$ (в СФО - 9,8\%), органов пищеварения - 8,3\% (в СФО $6,7 \%$ ), а также мочеполовой системы -6,7\% (в СФО - 6,7\%).

По сравнению с 2000 г. в 2015 г. в структуре заболеваемости населения Сибирского приграничья возросли доли по следующим классам причин: болезни органов пищеварения (на 2,1 п.п.), системы кровообращения (на 1,0 п.п.), эндокринной системы и нарушения обмена веществ (на 0,5 п.п.), травмы, отравления и несчастные случаи (на 0,5 п.п.), а также новообразования (на 0,3 п.п.).

Данные показатели свидетельствуют о том, что заболеваемость в Сибирском приграничье выросла не только количественно, но и качественно.

\section{Заболеваемость населения Сибирского приграничья и СФО по классам болезней, вносящим основной вклад в показатели смертности}

Болезни системы кровообращения. Заболеваемость болезнями системы кровообращения росла в 1995-2015 гг. наиболее быстрыми темпами: всего по РФ она увеличилась в 2,3 раза, по СФОв 2,7 раза, в то время как по другим округам - в 1,9-2,4 раза. В результате, если в 1995 г. СФО и РФ практически не различались по уровню заболеваемости этого класса, то в 2015 г. данные по округу превышали данные по РФ на $14 \%$. Кроме того, СФО длительное время занимал первое место по уровню этой заболеваемости среди всех округов РФ (лишь в 2015 г. его «обогнал» Приволжский федеральный округ). 
Тот факт, что при более молодой, чем в округах европейской части страны, структуре населения, в СФО - самые высокие растущие показатели заболеваемости болезнями системы кровообращения, говорит о том, что в Сибири эта заболеваемость более широко распространена среди молодого населения.

В Сибирском приграничье в 1995-2015 гг. заболеваемость болезнями системы кровообращения возросла в Новосибирской области в 3,9 раза, в остальных субъектах - от 1,5 до 3,2 раза. В Алтайском крае рост заболеваемости меньше - 1,8 раза, чем в среднем по СФО, из-за начавшегося с 2007 г. снижения заболеваемости по этому классу. Но, вследствие изначально высокого значения этого показателя, Алтайский край на протяжении всего периода прочно занимает первое место по заболеваемости болезнями системы кровообращения среди всех субъектов СФО. Однако, если в 1995 г. Алтайский край превосходил средний уровень заболеваемости по этому классу в округе почти в два раза, то в 2010 г. - на $69 \%$, а в 2015 г. - уже только на $29 \%$, т.е. разрыв сокращается. Омская область с 2008 г. по 2013 г. занимала второе место по заболеваемости болезнями системы кровообращения, в 2014 г. и 2015 г.- третье, пропустив вперед Новосибирскую область. Ситуация выглядела лучше до 2014 г. включительно в Республике Тыва, где заболеваемость по этому классу даже снизилась за рассматриваемый период на 5\%, но в 2015 г. вновь резко выросла. В 2015 г. в республиках Тыва, Бурятия и Томской области заболеваемость болезнями системы кровообращения была существенно ниже, чем в среднем по СФО.

Новообразования. За рассматриваемый период заболеваемость новообразованиями в СФО возросла в 2,2 раза (в РФ - в 1,7 раза). В 2015 г. округ превосходил РФ по заболеваемости новообразованиями на 19\%, при этом в 1995 г. значение показателя было даже ниже, чем в среднем по РФ. Положение СФО по отношению к другим округам постоянно ухудшалось, а с 2011 г. по 2015 г. он был лидером по печальной статистике среди округов РФ.

В Сибирском приграничье снова выделяется в худшую сторону Алтайский край, занимающий на протяжении практически всего рассматриваемого периода первое место среди субъектов СФО и превосходящий в 2015 г. средние по округу показатели заболеваемости новообразованиями на 53\%. В республиках же Тыва, Бурятия в 2015 г. показатель заболеваемости новообразованиями был ниже, чем в среднем по СФО.
Заболеваемость, связанная с травмами, отравлениями и некоторыми другими последствиями воздействия внешних причин, росла значительно меньшими темпами, чем две предыдущие. В 2015 г. по сравнению с 1995 г. по этому классу заболеваемость в СФО была на 10\% выше, в РФ - на 3\%. В 2011-2015 гг. округ занимал первое-второе места среди всех округов РФ, в 2015 г. заболеваемость в СФО была на $11 \%$ выше, чем по России в целом.

Заболеваемость населения территорий Сибирского приграничья по этому классу выглядит более благополучной относительно других регионов СФО. Так, в Омской области за рассматриваемый период она снизилась. В республиках Алтай, Бурятия, Тыва и в Забайкальском крае заболеваемость по данному классу ниже, чем в среднем по округу, но темпы ее роста-выше. Высоки они и в Новосибирской области - рост показателя за период составил $34 \%$.

\section{Особенности показателей смертности населения территорий \\ Сибирского приграничья и СФО}

Рост заболеваемости населения СФО происходил на фоне сокращающегося с 2006 г. уровня смертности и роста ожидаемой продолжительности жизни.

Во всех регионах СФО на протяжении нескольких последних лет ожидаемая продолжительность жизни отмечается ниже среднероссийской. При этом в Сибирском приграничье уровень выше 70 лет имели только регионы Сибирско-Казахстанского приграничья: Новосибирская и Омская области, а также Алтайский край. Все регионы Восточно-Сибирского приграничья характеризуются более низкой ожидаемой продолжительностью жизни, наихудшие показатели зафиксированы в Республике Тыва. При этом, однако, у нее - один из самых низких уровней регистрируемой заболеваемости в СФО (см. рисунок), а также устойчиво в течение длительного времени - самые низкие показатели заболеваемости болезнями системы кровообращения и новообразованиями. Казалось бы, можно предположить, что причина кроется в недостаточной выявляемости заболеваний.

Но если посмотреть показатели смертности по трем основным причинам смерти, то у Республики Тыва они в сумме самые низкие в СФО, причем значительно ниже средних (за исключением смертности от внешних причин, которая наоборот, почти в два 
раза выше среднесибирской) (табл. 1). Таким образом, объяснить низкую заболеваемость болезнями системы кровообращения и новообразованиями плохой выявляемостью, которая должна сопровождаться в таком случае повышенной смертностью по соответствующим классам, не получается.

При переходе к анализу стандартизованных коэффициентов смертности, нивелирующих особенности возрастной структуры населения, благополучная на вид картина радикально меняется. По всем трем основным причинам смерти Республика Тыва имеет худшие стандартизованные показатели во всем Сибирском приграничье. И если по новообразованиям смертность в ней на уровне среднесибирской, то по смертности от двух других основных классов причин смерти ситуация - наихудшая во всем СФО, причем с большим отрывом от других регионов: по стандартизованным показателям смертности от болезней системы кровообращения - в 1,4 раза, а по внешним причинам - в 2,2 раза выше средних по СФО.

Таким образом, основной причиной устойчиво низкой регистрируемой заболеваемости в Республике Тыва болезнями системы кровообращения и новообразованиями является существенно более молодая возрастная структура населения за счет самой высокой в стране рождаемости, приводящей к омоложению возрастной пирамиды снизу, и самой низкой в стране ожидаемой продолжительностью жизни, приводящей к ее омоложению сверху (табл. 2). Тем более что эти классы заболеваний характерны, прежде всего, для пожилого населения.

Высокий уровень смертности в республике обусловлен в значительной степени аномально высочайшей в стране смертностью от внешних причин, не связанных с заболеваниями: отравлений, травм, несчастных случаев, убийств и самоубийств.

Все вышесказанное, правда, в меньшей степени, касается и других регионов Восточно-Сибирского приграничья, у которых наблюдается несоответствие показателей заболеваемости и смертности: Республики Бурятия и Забайкальского края. Они также характеризуются более молодой возрастной структурой за счет относительно высокой рождаемости и продолжительностью жизни ниже среднесибирской. При рассмотрении стандартизованных показателей смертности от болезней системы

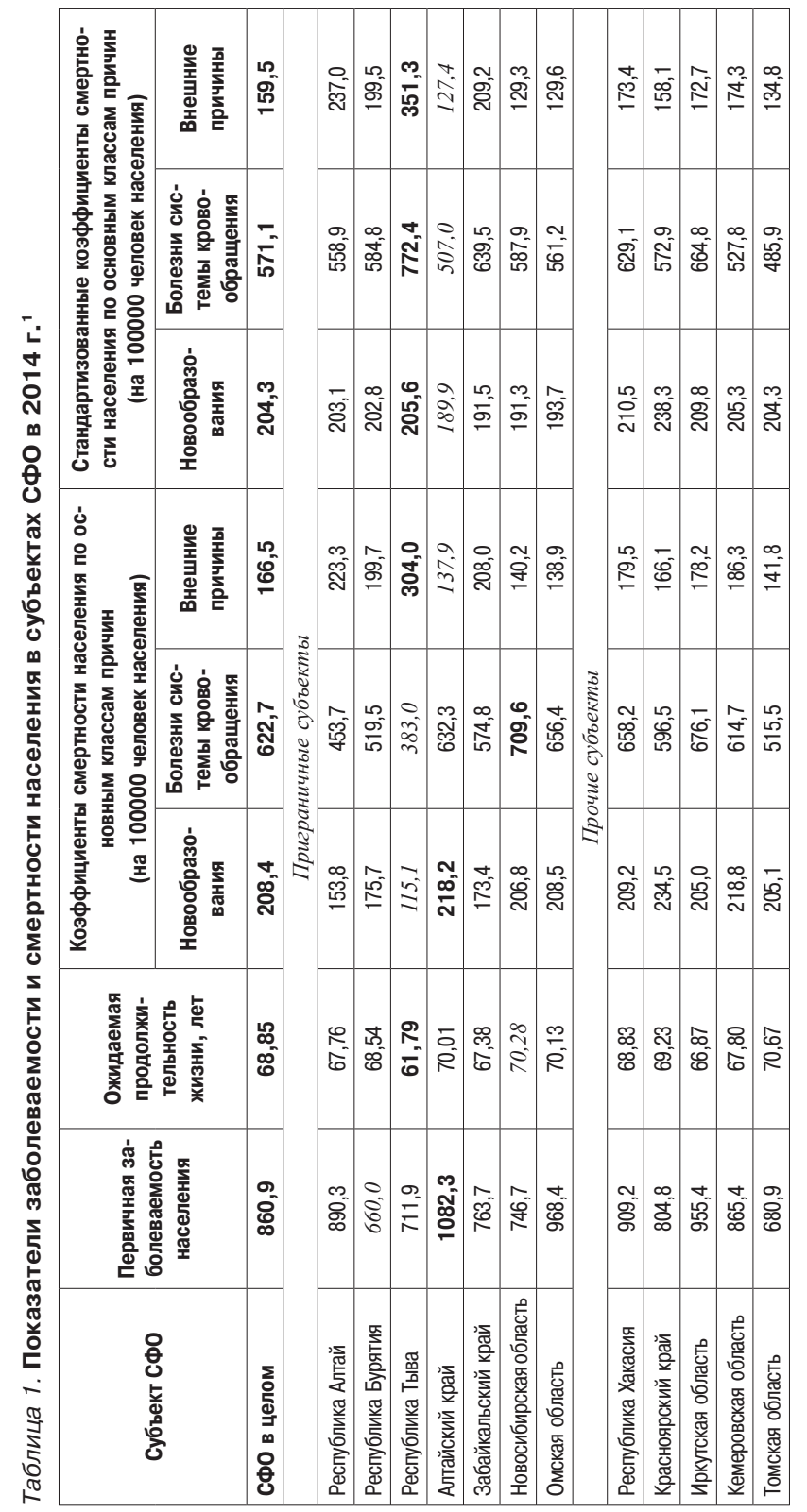


кровообращения и новообразований их позиции выглядят уже не лучшими, а на уровне среднесибирских.

Таблица 2. Рождаемость и возрастная структура населения в приграничных субъектах СФО в 2014 г.

\begin{tabular}{|c|c|c|c|c|c|}
\hline \multirow[b]{2}{*}{ Субъект СФО } & \multirow{2}{*}{$\begin{array}{c}\text { Суммарный } \\
\text { коэффициент } \\
\text { рождаемости }\end{array}$} & \multirow{2}{*}{$\begin{array}{c}\text { Средний } \\
\text { возраст на- } \\
\text { селения, лет } \\
\text { (на конец } \\
2014 \text { г.) }\end{array}$} & \multicolumn{3}{|c|}{$\begin{array}{c}\text { Доля возрастных групп в общей } \\
\text { численности населения,\% }\end{array}$} \\
\hline & & & $\begin{array}{c}\text { Муж. } \\
\text { и женщ. } \\
0-15 \\
\end{array}$ & $\begin{array}{l}\text { Муж. 16-59, } \\
\text { женщ.16-54 }\end{array}$ & $\begin{array}{c}\text { Муж. } 60 \text { и бо- } \\
\text { лее, женщ. } 55 \\
\text { и более }\end{array}$ \\
\hline $\begin{array}{l}\text { Сибирский } \\
\text { федеральный } \\
\text { округ }\end{array}$ & 1,902 & 38,1 & 19,4 & 58,2 & 22,4 \\
\hline $\begin{array}{l}\text { Республика } \\
\text { Алтай }\end{array}$ & 2,883 & 33,8 & 27,6 & 55,6 & 16,8 \\
\hline $\begin{array}{l}\text { Республика } \\
\text { Бурятия }\end{array}$ & 2,260 & 35,3 & 23,3 & 58,0 & 18,7 \\
\hline $\begin{array}{l}\text { Республика } \\
\text { Тьва }\end{array}$ & 3,485 & 29,3 & 33,5 & 55,9 & 10,6 \\
\hline $\begin{array}{l}\text { Алтайский } \\
\text { край }\end{array}$ & 1,841 & 39,8 & 18,3 & 56,4 & 25,3 \\
\hline $\begin{array}{l}\text { Забайкальский } \\
\text { край }\end{array}$ & 2,078 & 35,7 & 22,1 & 58,8 & 19,1 \\
\hline $\begin{array}{l}\text { Новосибирская } \\
\text { область }\end{array}$ & 1,765 & 39,3 & 17,2 & 59,0 & 23,8 \\
\hline Омская область & 1,951 & 38,9 & 18,2 & 58,6 & 23,2 \\
\hline
\end{tabular}

Для всех регионов Восточно-Сибирского приграничья свойственна самая высокая в стране печальная статистика смертности от внешних причин, кроме того, они имеют одни из самых высоких в России уровней смертности на 100000 человек населения: от отравления алкоголем (Республика Тыва - 23,0; Республика Бурятия - 21,9; СФО - 12,6; РФ - 9,6), от несчастных случаев на транспорте (Республика Тыва - 38,5 (первое место в стране); Забайкальский край - 20,1; СФО - 14,9; РФ - 14,7), от убийств (Республика Тыва - 33,1 (первое место в стране); Забайкальский край - 21,8; Республика Бурятия - 19,6; СФО - 12,3; РФ - 7,2) и самоубийств (Республика Бурятия - 47,4 (второе место в стране); Забайкальский край - 39,9; СФО - 25,5; РФ - 15,8). Все эти причины смертности прямо или опосредованно в значительной степени связаны с высоким уровнем алкоголизации населения в этих регионах.

Алтайский край, который имеет наихудшие показатели по заболеваемости и, прежде всего, болезнями системы кровообращения и новообразованиями при рассмотрении стандартизованных показателей смертности, наоборот, имеет самые лучшие показатели во всем Сибирском приграничье (см. табл. 1). В этом регионе возрастная структура самая «старая» в СФО - средний возраст населения приближается к 40 годам. В отличие от более молодого (на 10 лет) населения Республики Тыва, где треть составляют дети, а население старше трудоспособного возраста - всего 11\%, в Алтайском крае четверть населения - старше трудоспособного возраста, а доля детей - почти в два раза ниже, чем в Республике Тыва (см. табл. 2). Такая «старая» возрастная структура негативно влияет на показатели регистрируемой заболеваемости.

Таким образом, возрастная структура населения может оказывать значительное влияние на показатели заболеваемости, искажая в ту или иную сторону реальную ситуацию со здоровьем населения.

\section{Заключение}

Несмотря на рост ожидаемой продолжительности жизни в последние годы, ситуация с заболеваемостью в стране продолжает оставаться напряженной. Особенно плохо выглядит на общем фоне СФО - второе-третье место среди всех федеральных округов по заболеваемости населения в последние годы, а также устойчивые первые места по многим основным классам заболеваний, и в первую очередь по вносящим наибольший вклад в смертность и инвалидизацию населения. Причем в СФО первые места по заболеваемости болезнями системы кровообращения и новообразованиям сочетаются с более молодой возрастной структурой населения, чем в среднем по России, и особенно в Центральном и Северо-Западном федеральных округах. Старение населения может еще больше усилить негативные тенденции.

Таким образом, на фоне депопуляции в недавнем прошлом снижались не только количество населения, но и его качество за счет роста заболеваемости и старения, что создает неблагоприятные условия не только для воспроизводства населения, но и для экономики страны.

В состав Сибирского приграничья входит Алтайский край с самым высоким уровнем заболеваемости в СФО, на протяжении длительного времени удерживающий первые места по заболеваемости болезнями системы кровообращения и новообразованиям.

4 ЭКО. - 2017. - № 12 
Выглядящие более благополучно республики Тыва, Бурятия, а также Забайкальский край, характеризуются при этом пониженной ожидаемой продолжительностью жизни, то есть более высокой смертностью.

Однако при углубленном анализе с использованием стандартизованных коэффициентов смертности, нивелирующих влияние более молодой возрастной структуры населения в этих регионах, было установлено, что потенциальная смертность от трех классов заболеваний, вносящих основной вклад в смертность, в случае более старой возрастной структуры, принятой за стандарт, была бы отнюдь не самой низкой именно в этих регионах. Особенно это касается Республики Тыва с самыми худшими соответствующими показателями во всем Сибирском приграничье.

То есть ситуация со здоровьем населения в регионах Восточно-Сибирского приграничья вовсе не такая благополучная, как это кажется на первый взгляд. Пока реальное положение маскирует более молодая возрастная структура за счет относительно более высокой рождаемости, приводящей к омоложению возрастной пирамиды снизу, и низкой ожидаемой продолжительности жизни, приводящей к ее омоложению сверху.

\section{Литература}

1. Соболева С.В., Смирнова Н.Е., Чудаева О.В.Демографическая безопасность России: региональные измерители, оценка результатов // Мир новой экономики.- 2016.- № 4.- С. 142-153.

2. Соболева С.В., Смирнова Н.Е., Чудаева О.В. Многорегиональный анализ динамики демографических рисков на территории Сибири // Регион: экономика и социология.- 2016.- № 3 (91).- С. 76-97.

3. Соболева С.В., Смирнова Н.Е., Чудаева О. В.Миграция населения в приграничных регионах Сибири // ЭКО.- 2014.- № 8.- С. 18-31.

4. Соболева С.В., Григорьев Ю.А., Смирнова Н.Е., Чудаева О.В. Особенности формирования населения приграничных территорий Сибири // ЭКО.- 2014.- № 11.- С. 20-35.

5. Соболева С.В., Смирнова Н.Е., Чудаева О. В.Сибирско-Казахстанское приграничье как территория демографического риска // Вестник НГУЭУ.2016.- № 3.- С. 26-40.

6. Соболева С.В., Смирнова Н.Е., Чудаева О. В. Здоровье населения Сибири: риски и их измерители // Регион: экономика и социология.- 2010.- № 2.C. 223-241.

7. Соболева С.В., Смирнова Н.Е., Чудаева О.В. Риски в формировании демографического потенциала Сибири // Регион: экономика и социология.2011.- № 4.- С. 98-115.

8. Соболева С.В., Смирнова Н.Е., Чудаева О. В. Здоровье населения Сибири // Перспективы и риски развития человеческого потенциала в Сибири / отв. ред. акад. В. В. Кулешов.- Новосибирск: Изд-во СО РАН, 2014.- Гл. 13.- С. 227-254. 